\title{
TRATAMENTO COM HIPOCLORITO DE SÓDIO PARA REMOÇÃO DO PERGAMINHO E ACELERAÇÃO DA GERMINAÇÃO DE SEMENTES DE CAFÉ CONILON ${ }^{1}$
}

\author{
RAQUEL FIALHO RUBIM², HENRIQUE DUARTE VIEIRA ${ }^{3}$ EDUARDO FONTES ARAÚJO4, \\ ALEXANDRE PIO VIANA ${ }^{3}$, FÁBIO CUNHA COELHO ${ }^{3}$
}

\begin{abstract}
RESUMO - Este trabalho foi desenvolvido com objetivo de avaliar o efeito do hipoclorito de sódio na remoção do pergaminho e na aceleração da germinação de sementes de café conilon. As sementes, cultivar Vitória, foram obtidas de frutos colhidos no estádio cereja e despolpados manualmente. As sementes foram secadas em estufa de ventilação forçada até atingirem os graus de umidade de 35, 30 e 25\% em base úmida. Em seguida, as sementes com pergaminho foram submetidas à solução de hipoclorito de sódio nas concentrações de 4, 5, 6 e 7\% de cloro ativo por períodos de 3 e 6 horas. Para cada grau de umidade foram acrescentados três tratamentos adicionais, constituídos por sementes intactas com pergaminho e sementes cujo pergaminho foi removido mecânica e manualmente. As sementes foram avaliadas pelas seguintes determinações: grau de umidade, germinação, primeira contagem do teste de germinação e índice de velocidade de germinação. $\mathrm{O}$ delineamento experimental foi o inteiramente ao acaso, em esquema fatorial 3 (graus de umidade inicial) x 4 (concentrações de hipoclorito de sódio) x 2 (tempos de imersão) + 9 (tratamentos adicionais), com quatro repetições. O hipoclorito de sódio na concentração de 6\% por 3 horas proporciona germinação e índice de velocidade de germinação estatisticamente igual ao método de remoção manual do pergaminho, o qual é usado em laboratório. A remoção mecânica do pergaminho danifica as sementes de café, prejudicando a germinação.
\end{abstract}

Termos para indexação: Coffea canephora, vigor, IVG, qualidade fisiológica.

\section{SODIUM HYPOCHLORITE TREATMENT TO REMOVE THE PARCHMENT AND ACCELERATE GERMINATION OF CONILON COFFEE SEEDS}

\begin{abstract}
The objective of this study was to evaluate the effect of sodium hypochlorite on the removal of the parchment and the acceleration of conilon coffee seed germination. Seeds of the Vitoria cultivar were obtained from fruits harvested at the cherry stage and pulped by hand. They were dried in a forced ventilation oven until 35, 30 and 25\% moisture content on a wet basis. Sodium hypochlorite solution in concentrations of 4, 5, 6 and 7\% active chlorine was applied
\end{abstract}

${ }^{1}$ Submetido em 01/07/2009. Aceito para publicação em 07/07/2010. Parte da dissertação de Mestrado do primeiro autor apresentada na UENF.

${ }^{2}$ Eng. Agr., pós graduanda do Labor. Fitotecnia, UENF, e-mail: raquel_ rubim@yahoo.com.br.
${ }^{3}$ Eng. Agr., Dr. Professor Associado, Centro Ciências e Tecnologia Agropecuária, UENF, CEP: 28013-600, Capus dos Goitacazes, e-mail: henrique@uenf.br, pirapora@uenf.br, fcoelho@uenf.br

${ }^{4}$ Eng. Agr., Dr. Professor Associado II, Depto Fitotecnia, UFV, CEP: 36570-000, Viçosa-MG, e-mail: efaraujo@ufv.br 
to those seeds with parchment for periods of 3 and 6 hours. For each moisture content, there were three additional treatments consisting of seeds with parchment and seeds whose parchments had been removed mechanically and manually. The seeds were evaluated for: moisture content, germination, first count of the germination test and speed of the germination index. The experiment was a completely randomized design in a factorial 3 (degrees of water content) $\mathrm{x} 4$ (concentrations of sodium hypochlorite) x 2 (time of immersion) +9 (additional treatments) with four replications. Sodium hypochlorite at a concentration of $6 \%$ for 3 hours caused germination and a speed of germination index similar to the method of manual removal of the parchment, which is used in the laboratory. The mechanical removal of the parchment damaged coffee seeds, reducing their germination.

Index terms: Coffea canephora, vigour, SGI, physiological quality.

\section{INTRODUÇ̃̃OO}

O café conilon brasileiro possui grande importância nas exportações, na industrialização como café torrado e moído em misturas com café arábica e, principalmente, na industrialização como café solúvel (Seagri, 2008).

Contudo, um dos principais problemas na produção de mudas de café refere-se à germinação lenta e desuniforme de suas sementes (Guimarães e Mendes, 1998). Trabalhos vêm sendo realizados, principalmente com café arábica, para esclarecer as causas que venham a provocar a desuniformidade e a baixa velocidade da germinação dessas sementes. Porém, mais estudos são necessários para elucidar os mecanismos que trazem tais prejuízos ao processo germinativo, especialmente com café conilon, uma vez que as informações são mais escassas.

A presença do endocarpo, um envoltório delgado, duro e coreáceo, conhecido por pergaminho, é uma das prováveis causas da lenta germinação de sementes de café. No entanto, ainda não se sabe a real inibição causada pelo pergaminho. Segundo Valio (1980), essa inibição não é devido à insuficiência na absorção de água, mas sim a algum mecanismo de resistência imposto pelo pergaminho sobre o desenvolvimento do embrião.

Araújo et al. (2004) concluíram que a retirada do pergaminho é eficiente para acelerar a germinação de sementes de café arábica. Segundo os mesmos autores, a remoção dessa estrutura deve ser realizada de forma cuidadosa, uma vez que o embrião encontra-se localizado em camada muito superficial nas sementes. A remoção mecânica, normalmente, provoca danos ao embrião. Por outro lado, a remoção manual é um procedimento bastante trabalhoso, já que as sementes são manuseadas individualmente, causando empecilhos à sua utilização, principalmente entre os viveiristas que manipulam um grande volume de sementes.

O desenvolvimento de um método que possa remover o pergaminho de forma eficiente, prática e com baixo custo, acelerando e, ou, uniformizando a germinação de sementes de café, trará grande benefício para os produtores e viveiristas. $\mathrm{O}$ uso de produtos químicos em sementes de diferentes espécies, com o objetivo de escarificar seus tegumentos ou envoltórios, estimular a germinação ou atuar em mecanismos de dormência, tem sido cada vez maior (Meireles et al., 2007).

A remoção do pergaminho utilizando solução de hipoclorito de sódio vem proporcionando resultados bastante promissores em sementes de café arábica, além de ser um produto de baixo custo e de fácil manuseio. Meireles et al. (2007) concluíram que o uso do hipoclorito de sódio na concentração de $5 \%$ de cloro ativo, durante um período de 6 horas, além de degradar o pergaminho de forma eficiente, proporcionou melhor germinação de sementes de café arábica com grau de umidade inicial de $28 \%$, em condições de laboratório. Trabalhos realizados por Sofiatti et al. (2008) mostraram que a pré-embebição de sementes de café arábica, com graus de umidade de 23,28 e $33 \%$, em hipoclorito de sódio contendo $6 \%$ de cloro ativo durante 3 horas, foi eficiente na degradação do pergaminho, sem causar danos ao embrião, proporcionando percentagem e velocidade de germinação semelhantes a remoção manual do pergaminho.

Desta forma, o presente trabalho foi realizado com objetivo de avaliar combinações entre concentrações de 
hipoclorito de sódio e tempos de imersão que proporcionem maior velocidade de germinação de sementes de café conilon em condições de laboratório.

\section{MATERIAL E MÉTODOS}

Os experimentos foram realizados no Setor de Tecnologia de Sementes do Laboratório de Fitotecnia do Centro de Ciências e Tecnologias Agropecuárias (CCTA) da Universidade Estadual do Norte Fluminense Darcy Ribeiro, em Campos dos Goytacazes - RJ.

As sementes de café conilon (Coffea canephora Pierre), cultivar Vitória, foram obtidas de frutos colhidos no estádio cereja, provenientes de lavouras comerciais. Após a colheita, os frutos foram levados para o laboratório e imediatamente submetidos ao processo manual de despolpamento.

Seguido ao despolpamento, foi realizada a secagem das sementes em estufa de ventilação forçada à temperatura de $36{ }^{\circ} \mathrm{C}$, até os graus de umidade de 35,30 e $25 \%$ em base úmida. Com estas umidades, as sementes com pergaminho foram embebidas em solução de hipoclorito de sódio nas concentrações de 4, 5, 6 e 7\% de cloro ativo. Para cada concentração, as sementes foram imersas na solução por períodos de 3 e 6 horas. As soluções de cloro ativo do hipoclorito de sódio, nas diferentes concentrações, foram preparadas próximo ao momento de sua utilização.

As sementes foram acondicionadas em caixas gerbox contendo solução de hipoclorito de sódio, adotando-se a proporção de $125 \mathrm{~mL}$ de solução para 250 sementes. Para que as sementes permanecessem imersas na solução, foi utilizado o telado próprio das caixas gerbox, as quais foram tampadas e levadas para uma BOD com temperatura constante de $25^{\circ} \mathrm{C}$ na ausência de luz, onde permaneceram pelos períodos referentes a cada tratamento (Sofiatti et al., 2008). Após cada período de imersão, as sementes foram lavadas em água corrente. Para cada grau de umidade, foram acrescentados três tratamentos adicionais constituídos por sementes intactas com pergaminho e sementes cujos pergaminhos foram removidos manual e mecanicamente, utilizando-se a máquina de descascar café Pinhalense tipo DRC-1.

Após os tratamentos, as sementes foram submetidas aos seguintes testes:

Grau de umidade: Foi determinado por meio do método da estufa a $105 \pm 3{ }^{\circ} \mathrm{C}$ durante 24 horas, utilizandose 2 amostras de $5 \mathrm{~g}$ para cada tratamento, conforme as Regras para Análise de Sementes (Brasil, 1992), sendo os resultados expressos em percentagem de umidade em base úmida.

Teste de germinação: Foram utilizadas 4 repetições de 50 sementes semeadas em rolo de papel tipo germiteste umedecidos com quantidade de água destilada equivalente a 2,5 vezes o peso do substrato seco. Os rolos foram mantidos em germinador à temperatura de $30{ }^{\circ} \mathrm{C}$ constante. A avaliação das plântulas foi realizada 30 dias após a instalação do teste, de acordo com as Regras para Análise de Sementes (Brasil, 1992), sendo os resultados obtidos expressos em percentagem de plântulas normais.

Primeira contagem do teste de germinação: Realizado quinze dias após o início do teste de germinação, segundo as Regras para Análise de Sementes (Brasil, 1992), onde foram consideradas germinadas as sementes que apresentaram protrusão da raiz primária, expressando-se os resultados em percentagem.

Índice de velocidade de germinação (IVG): Foi avaliado durante a condução do teste de germinação, sendo as avaliações realizadas a cada 3 dias, a partir do dia em que as primeiras sementes emitiram radícula até o dia da última contagem do teste de germinação. Para o cálculo, foi utilizada a fórmula proposta por Maguire (1962).

Análise estatística: $\mathrm{O}$ delineamento experimental adotado foi o inteiramente casualizado, com quatro repetições em esquema fatorial $3 \times 4 \times 2+9$, ou seja, três graus de umidade inicial, quatro concentrações de hipoclorito de sódio, dois tempos de imersão e mais nove tratamentos adicionais (sementes intactas com pergaminho, sementes cujos pergaminhos foram removidos manual e mecanicamente, em cada umidade). Para as variáveis quantitativas que apresentaram efeito significativo pelo teste $\mathrm{F}$ foi realizada a análise de regressão. Os tratamentos em arranjo fatorial foram comparados aos tratamentos adicionais aplicando-se o teste de Tukey a 5\% de probabilidade.

\section{RESULTADOS E DISCUSSÃO}

Como não houve diferença significativa entre os diferentes graus de umidade para os tratamentos adicionais nos níveis de 1 e $5 \%$ de probabilidade, utilizou-se, para os tratamentos adicionais, em todas as características avaliadas, a média das variáveis observadas nas três umidades iniciais.

Na Tabela 1 encontram-se os valores das umidades apresentadas pelas sementes, após a embebição em solução de hipoclorito de sódio nas concentrações de 4, 5, 6 e 
$7 \%$ de cloro ativo, durante os períodos de 3 e 6 horas. As testemunhas não estão descritas na tabela, uma vez que não receberam o tratamento, estando, no momento da realização do teste, com umidades de 35,30 e $25 \%$.

TABELA 1. Grau de umidade de sementes de café submetidas a quatro concentrações de hipoclorito de sódio por períodos de 3 e 6 horas, com diferentes graus de umidade inicial.

\begin{tabular}{ccccc}
\hline \multirow{2}{*}{ Concentração (\%) } & Tempo (h) & \multicolumn{3}{c}{ Grau de umidade inicial das sementes } \\
\cline { 3 - 5 } & 3 & 25 & 30 & 35 \\
\hline \multirow{2}{*}{4} & 6 & 35,3 & 36,8 & 42,2 \\
& 3 & 37,6 & 40,4 & 47,8 \\
\hline \multirow{2}{*}{5} & 6 & 38,5 & 40,5 & 44,5 \\
& 3 & 39,3 & 42,2 & 46,7 \\
\hline \multirow{2}{*}{6} & 6 & 42,0 & 44,3 & 47,7 \\
& 3 & 42,0 & 44,8 & 50,8 \\
\hline \multirow{2}{*}{7} & 6 & 42,2 & 47,5 & 50,7 \\
& & 42,8 & 47,2 & 51,1 \\
\hline
\end{tabular}

Sementes com menor grau de umidade inicial apresentaram maior absorção da solução de hipoclorito de sódio. Esses resultados corroboram com Sofiatti et al. (2008) que utilizando sementes de café arábica com graus de umidade inicial de $13,18,23,28$ e $33 \%$, observaram que, nas umidades de 13 e $18 \%$, as sementes absorveram mais solução, quando comparadas com as demais umidades.

As sementes tratadas com hipoclorito de sódio nas concentrações de 6 e 7\% apresentaram maior grau de umidade. Esses resultados estão de acordo com Meireles et al. (2007), os quais observaram maior grau de umidade em sementes submetidas à solução de hipoclorito de sódio nas concentrações de 7,5 e $10 \%$ e com Sofiatti et al. (2008) em concentrações de 6 e 7\%. Segundo Meireles (2004), concentração elevada de hipoclorito de sódio pode provocar escarificação tanto no pergaminho quanto em camadas mais profundas da semente, facilitando o ganho de umidade.

Avaliando-se os efeitos do tempo de exposição das sementes na solução de hipoclorito de sódio, se observa que no período de 6 horas a percentagem de germinação aumenta até os valores de 4,78 e 4,28\% de cloro ativo, para as umidades de 35 e 30\%, respectivamente (Figuras 1 e 2), valores estes obtidos pela primeira derivada das equações de regressão de $2^{\circ}$ grau. A partir destes valores, a germinação diminui à medida que a concentração do hipoclorito de sódio aumenta. Para a umidade inicial de
25\% (Figura 3), a germinação das sementes não apresenta este aumento, ou seja, ela diminui com o aumento das concentrações. No tempo de 3 horas de embebição das sementes à solução de hipoclorito de sódio, a percentagem de germinação aumenta até as concentrações de 6,$06 ; 6,09$ e $6,15 \%$ para as umidades de 35,30 e $25 \%$, respectivamente (Figuras 1, 2 e 3), podendo ser observado uma tendência de declínio na germinação a partir dessas concentrações. Com isso, verifica-se que o período de embebição de 3 horas promove melhor percentagem de germinação em concentrações maiores de solução de hipoclorito de sódio.

Sementes submetidas à solução aquosa de hipoclorito de sódio na concentração de $4 \%$ por 3 horas mostraram baixa germinação, uma vez que não ocorreu degradação completa do pergaminho, como foi observado visualmente após a aplicação do tratamento, em todas as umidades. Concentrações mais elevadas de hipoclorito de sódio (6 e 7\%) por período de tempo de 6 horas causaram redução na germinação, pois além da eliminação completa do pergaminho, o hipoclorito de sódio pode ter danificado estruturas essenciais da semente, como o embrião, já que este se encontra em camada superficial. Segundo Carnelossi et al. (1995), em certas sementes, cujos tegumentos não representam barreira física para a germinação, o hipoclorito de sódio pode causar escarificação, provocando dano aos tecidos do embrião. 


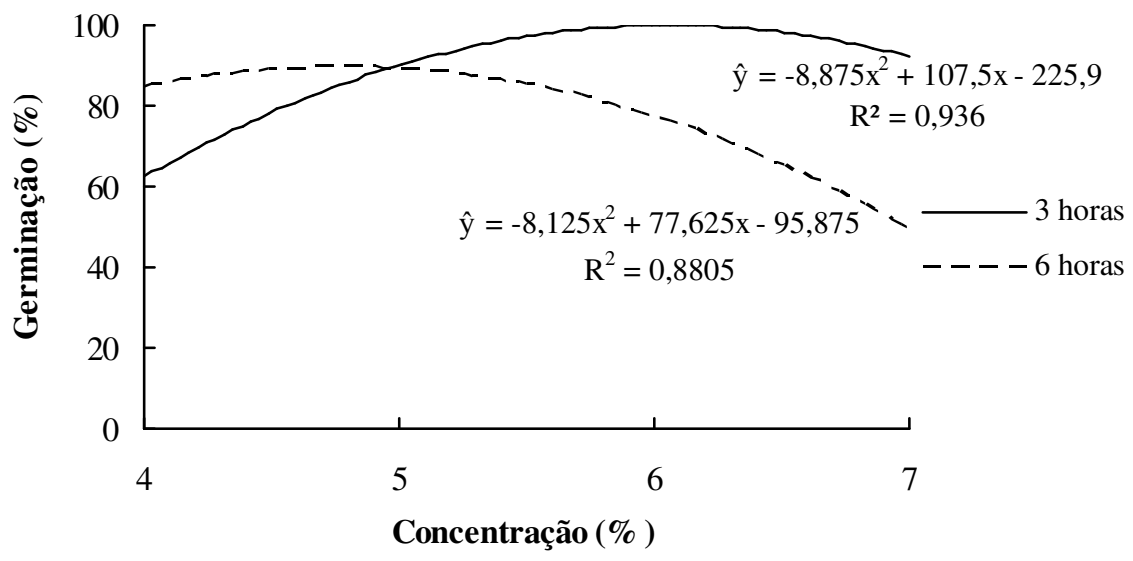

FIGURA 1. Germinação de sementes de café com umidade inicial de $35 \%$, após tratamento com hipoclorito de sódio nas concentrações de 4, 5, 6 e 7\% por períodos de 3 e 6 horas.

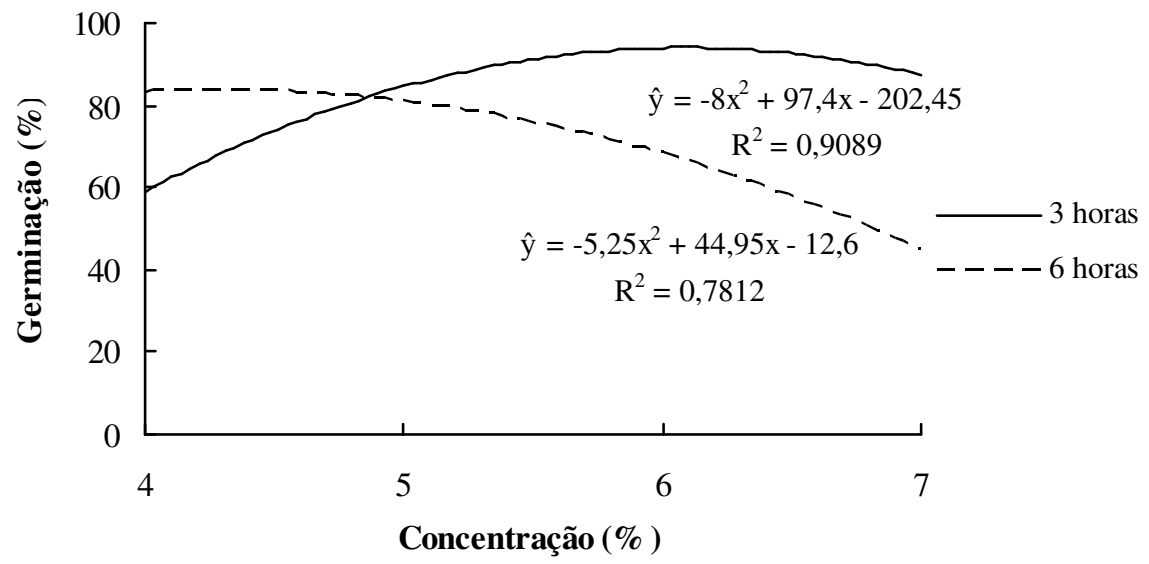

FIGURA 2. Germinação de sementes de café com umidade inicial de $\mathbf{3 0 \%}$, após tratamento com hipoclorito de sódio nas concentrações de 4, 5, 6 e 7\% por períodos de 3 e 6 horas.

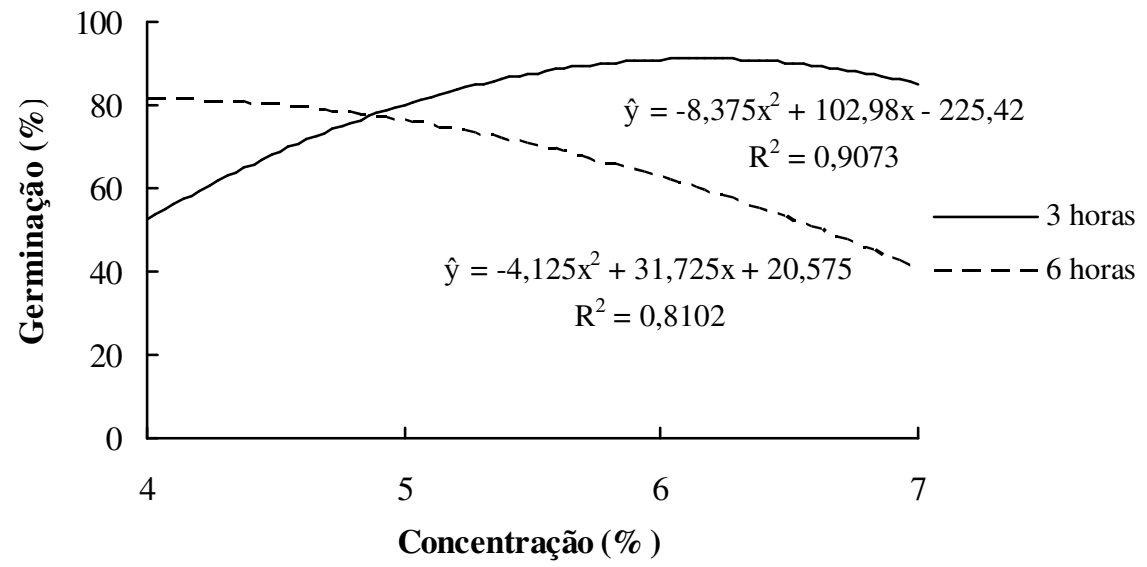

FIGURA 3. Germinação de sementes de café com umidade inicial de $25 \%$, após tratamento com hipoclorito de sódio nas concentrações de 4, 5, 6 e 7\% por períodos de 3 e 6 horas. 
Na Tabela 2, observa-se que a germinação das sementes com graus de umidade de 30 e $35 \%$ submetidas à solução de hipoclorito de sódio nas concentrações de 5, 6 e 7\% durante 3 horas e na concentração de $5 \%$ por 6 horas não diferiu estatisticamente do tratamento adicional cuja remoção do pergaminho foi realizada manualmente, demonstrando que, além de degradar o pergaminho de forma eficiente, não causou prejuízos para a germinação das sementes. Para as sementes com $25 \%$ de umidade, o hipoclorito de sódio nas concentrações de $5 \%$ por 6 horas e 6 e $7 \%$ por 3 horas também proporcionou germinação semelhante ao método de remoção manual do pergaminho.

TABELA 2. Germinação de sementes de café conilon com graus de umidade inicial de 25,30 e 35\%, após tratamento de remoção do pergaminho.

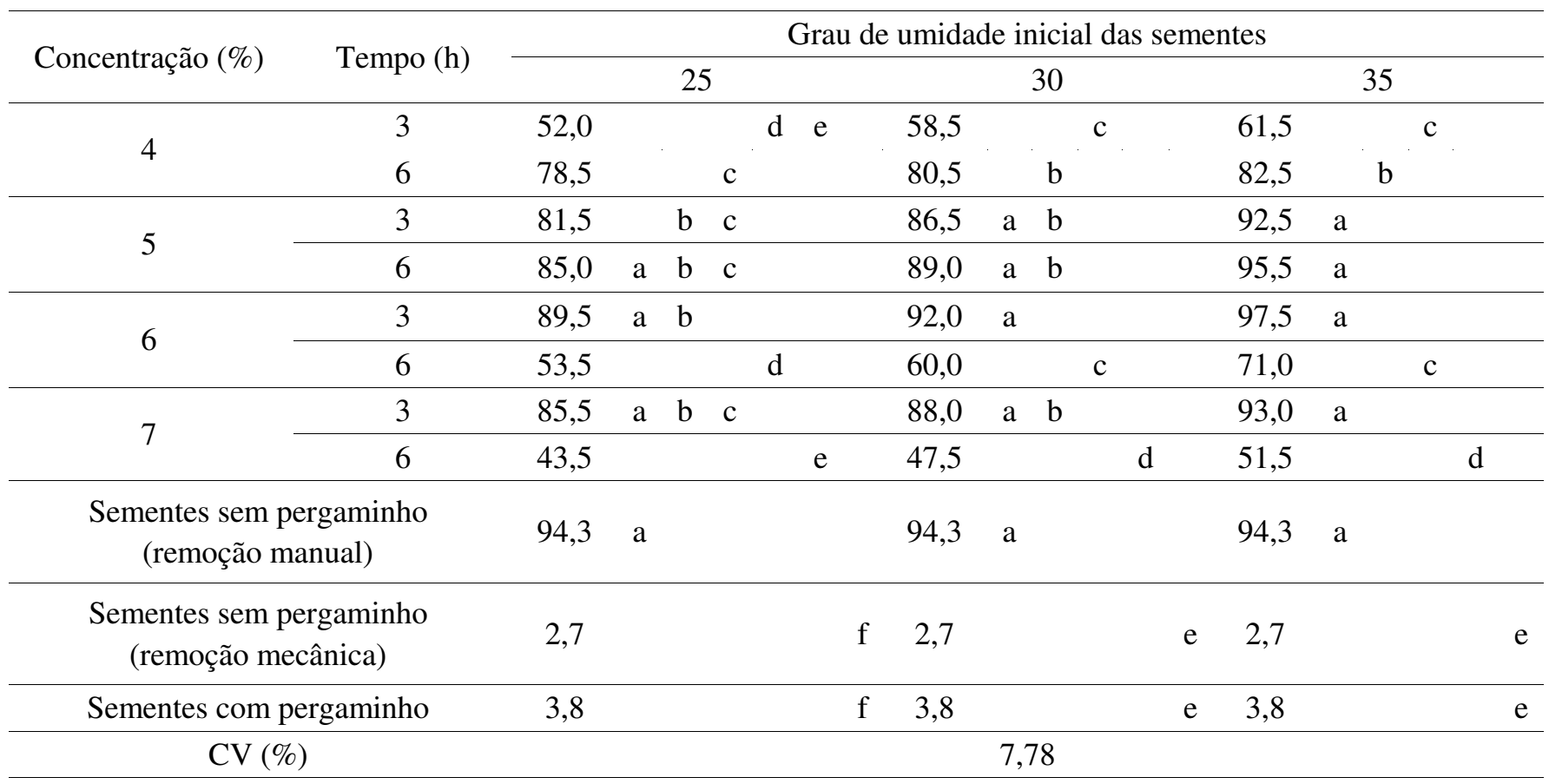

Médias seguidas pela mesma letra na coluna não diferem entre si ao nível de 5\% de probabilidade pelo teste de Tukey.

Esses resultados corroboram com Meireles et al. (2007), os quais observaram que sementes de café arábica com umidade inicial de $28,14 \%$, submetidas à solução de hipoclorito de sódio na concentração de $5 \%$ por 6 horas, apresentaram resultados semelhantes à remoção manual do pergaminho.

Sofiatti et al. (2008) mostraram que a solução de hipoclorito de sódio na concentração de $6 \%$ por 3 horas degradou eficientemente o pergaminho sem causar dano às sementes de café arábica com grau de umidade entre 23 e $33 \%$, concordando com os resultados mostrados na Tabela 2.

Ainda na Tabela 2, em todos os graus de umidade, o tratamento em solução de hipoclorito de sódio na concentração de $7 \%$ por 6 horas apresentou o pior desempenho, provavelmente devido à maior absorção da solução (Tabela 1). Isso demonstra que concentrações elevadas de hipoclorito de sódio, por períodos prolongados, prejudicama germinação de sementes de café, possivelmente por causar dano aos tecidos do embrião, uma vez que o hipoclorito de sódio é um forte oxidante (Bewley e Black, 1982).

A percentagem de germinação das sementes com pergaminho foi muito baixa em todas as umidades. Franco (1970) observou que, em meio asséptico, as sementes de café com pergaminho apresentam baixa germinação devido à ausência de microrganismos capazes de decompor o pergaminho. Como a condução do experimento foi feita em condições desfavoráveis ao desenvolvimento de microrganismos, isso explica a baixa germinação das sementes. 
Sementes cujo pergaminho foi removido mecanicamente apresentaram resultado similar ao das sementes com pergaminho, no entanto, por outro motivo. As sementes que tiveram o pergaminho removido mecanicamente apresentaram baixa germinação provavelmente devido aos danos mecânicos causados pelo equipamento, em razão do impacto das mesmas com as peneiras descascadoras, fato observado em sementes de café arábica por Araújo et al. (2004). Resultados semelhantes também foram observados em sementes de feijão submetidas a choques mecânicos em três níveis de velocidade $\left(16,5 ; 13,0\right.$ e $\left.10,0 \mathrm{~m} \cdot \mathrm{s}^{-1}\right)$, as quais tiveram queda na sua qualidade fisiológica com o aumento da velocidade de impacto (Andrade et al., 1999).
Observa-se, pelas regressões, que no período de exposição das sementes em solução de hipoclorito de sódio por 3 horas, o vigor aumenta até as concentrações de 6,10 e $6,30 \%$ para as umidades de 35 e $30 \%$, respectivamente (Figuras 4 e 5). A partir dessas concentrações, ocorre uma diminuição. Em sementes com umidade de $25 \%$ (Figura 6), o vigor aumenta em função da concentração de hipoclorito de sódio, até a concentração máxima testada.

Considerando ainda o tempo de 3 horas em solução de hipoclorito de sódio (Figuras 4, 5 e 6), nota-se que na concentração de $4 \%$ as sementes tiveram baixo desempenho, o que também pode ser observado pela Tabela 3. Isso ocorreu porque essa concentração não foi suficiente para a completa remoção do pergaminho.

TABELA 3. Primeira contagem de germinação de sementes de café conilon com graus de umidade inicial de 25,30 e 35\%, após tratamento de remoção do pergaminho.

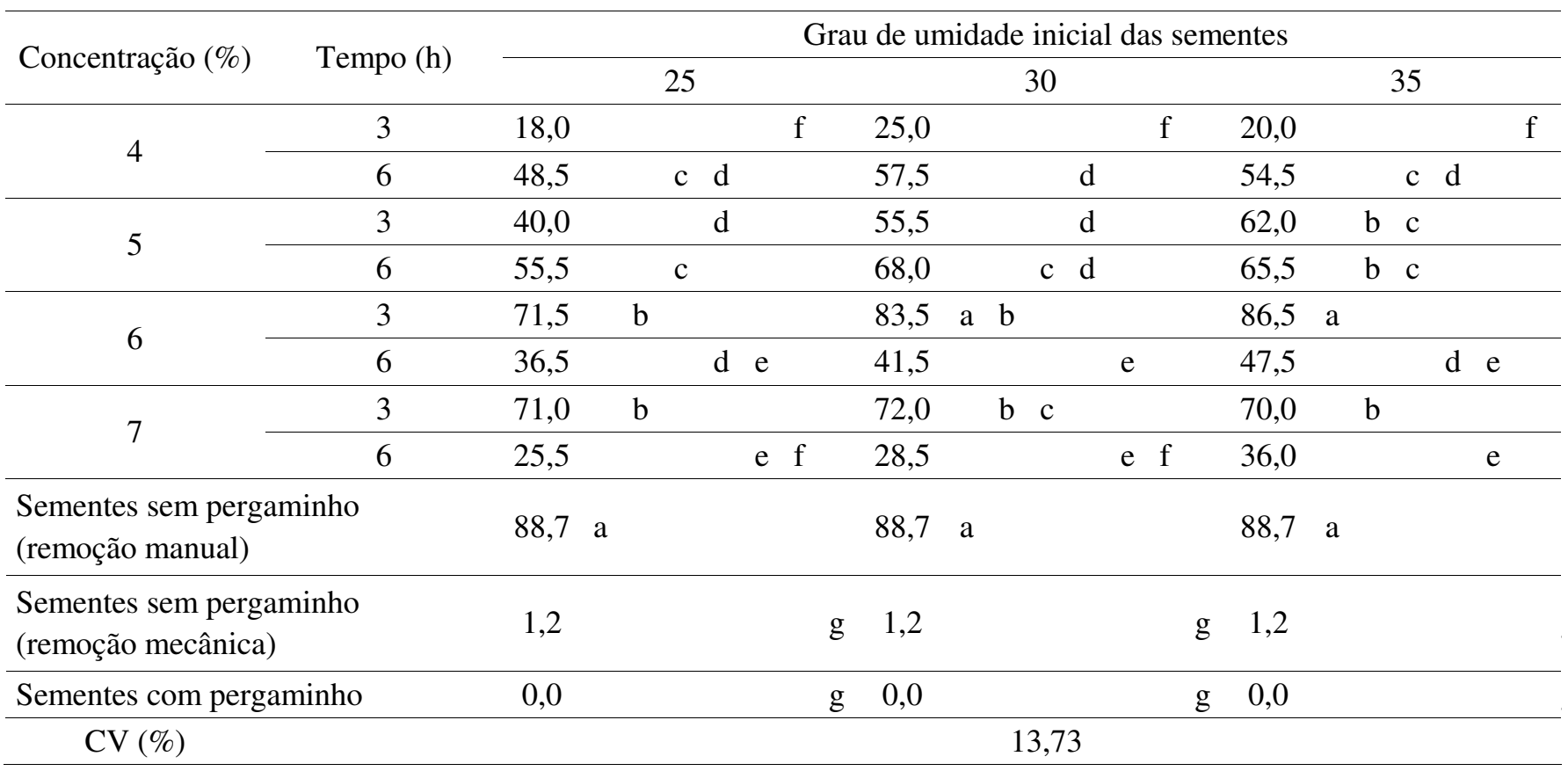

Médias seguidas pela mesma letra na coluna não diferem entre si ao nível de 5\% de probabilidade pelo teste de Tukey.

No tempo de 6 horas de imersão em solução de hipoclorito de sódio, o vigor aumentou até as concentrações de 4,$85 ; 4,53$ e $4,52 \%$, para as umidades de 35,30 e $25 \%$, respectivamente (Figuras 4, 5 e 6), apresentando, a partir daí, um decréscimo à medida que a concentração aumenta.

O tratamento com concentração de $7 \%$ por 6 horas causou baixo vigor em todas as umidades. Isso indica que a exposição das sementes de café conilon em solução de hipoclorito de sódio com alta concentração por períodos mais longos pode causar danos irreversíveis ao embrião. Entretanto, Meireles et al. (2007) observaram que sementes de café arábica expostas as concentrações de 7,5 e $10 \%$ de hipoclorito de sódio apresentaram altas taxas de vigor na primeira contagem, embora a germinação tenha sido prejudicada nessas concentrações, indicando que as sementes de café conilon sejam mais sensíveis a concentrações mais elevadas de hipoclorito de sódio. 


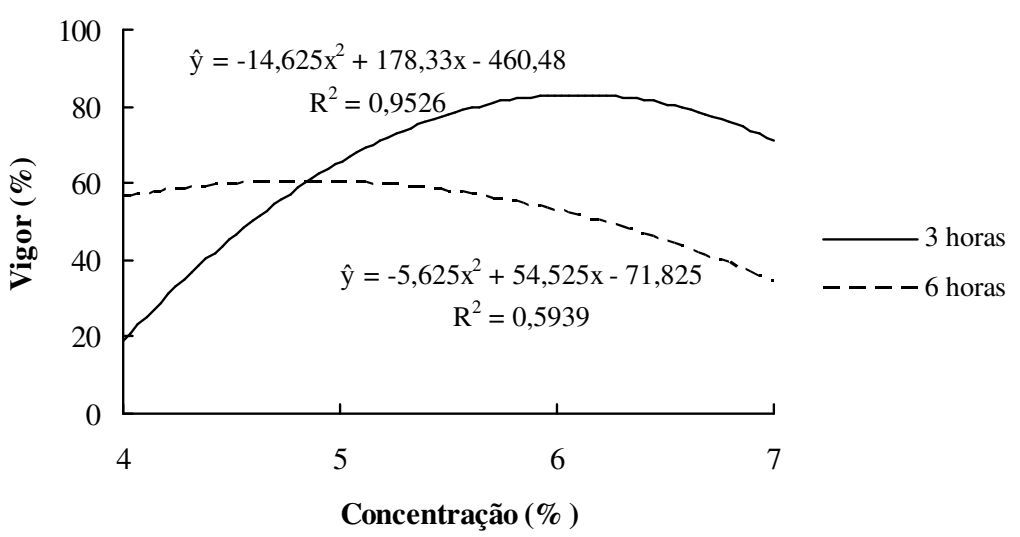

FIGURA 4. Vigor, pelo teste de primeira contagem de germinação, de sementes de café com umidade inicial de $35 \%$, após tratamento com hipoclorito de sódio nas concentrações de 4, 5, 6 e 7\% por períodos de 3 e 6 horas.

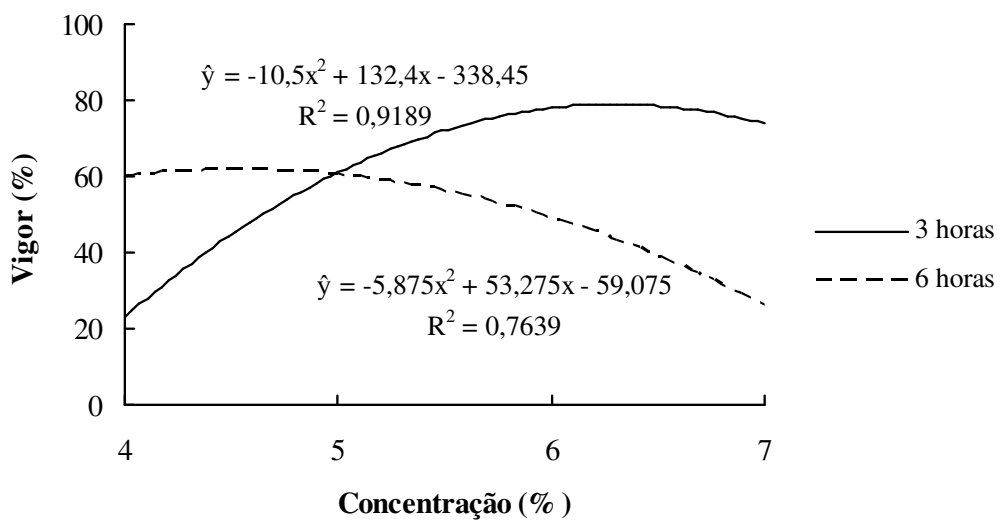

FIGURA 5. Vigor, pelo teste de primeira contagem de germinação, de sementes de café com umidade inicial de $30 \%$, após tratamento com hipoclorito de sódio nas concentrações de 4, 5, 6 e 7\% por períodos de 3 e 6 horas.

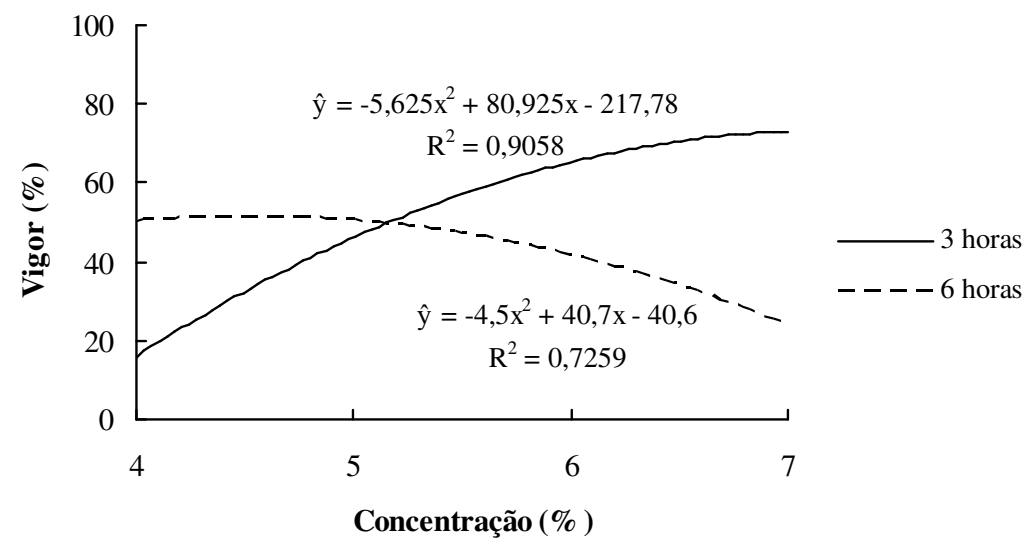

FIGURA 6. Vigor, pelo teste de primeira contagem de germinação, de sementes de café com umidade inicial de $25 \%$, após tratamento com hipoclorito de sódio nas concentrações de $4,5,6$ e $7 \%$ por períodos de 3 e 6 horas. 
Na Tabela 3, verifica-se que em sementes com graus de umidade de 30 e $35 \%$, o vigor das sementes embebidas em solução de hipoclorito de sódio na concentração de $6 \%$ durante 3 horas foi semelhante ao do tratamento adicional sem o pergaminho (remoção manual), o qual atingiu o máximo vigor.

Sementes com pergaminho e sem pergaminho removido mecanicamente não diferiram entre si estatisticamente, obtendo os piores resultados em todas as variáveis analisadas. Araújo et al. (2004) observaram que o uso de escarificador elétrico de paletas também causou danos às sementes de café arábica, impedindo a emergência das plântulas, os quais ocorreram em função do nível de danificação provocada pelos impactos mecânicos.

Para o período de 3 horas de imersão em solução de hipoclorito de sódio, as sementes tiveram aumento no IVG até as concentrações de 6,07; 6,36 e 6,94\% de hipoclorito de sódio e após estes valores apresentaram uma diminuição, para os graus de umidade de 35,30 e $25 \%$, respectivamente. Para o período de 6 horas, os maiores índices de velocidade de germinação foram observados nas concentrações de 4,64; 4,42 e 4,30\% de hipoclorito de sódio, para as umidades de 35,30 e $25 \%$, respectivamente. A partir destes valores, ocorreu decréscimo no IVG (Figuras 7, 8 e 9).

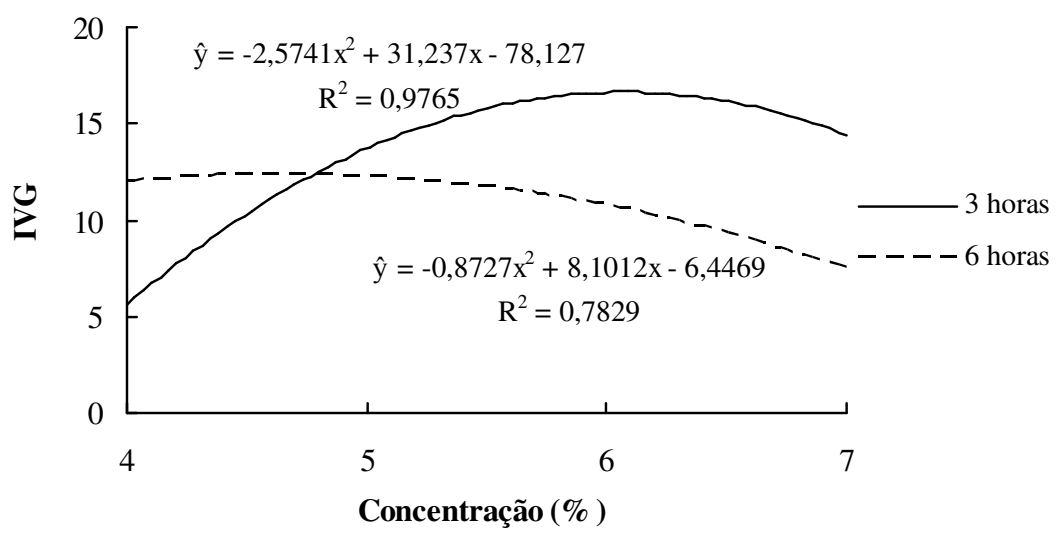

FIGURA 7. Índice de velocidade de germinação de sementes de café com umidade inicial de $35 \%$, após tratamento com hipoclorito de sódio nas concentrações de 4, 5, 6 e 7\% por períodos de 3 e 6 horas.

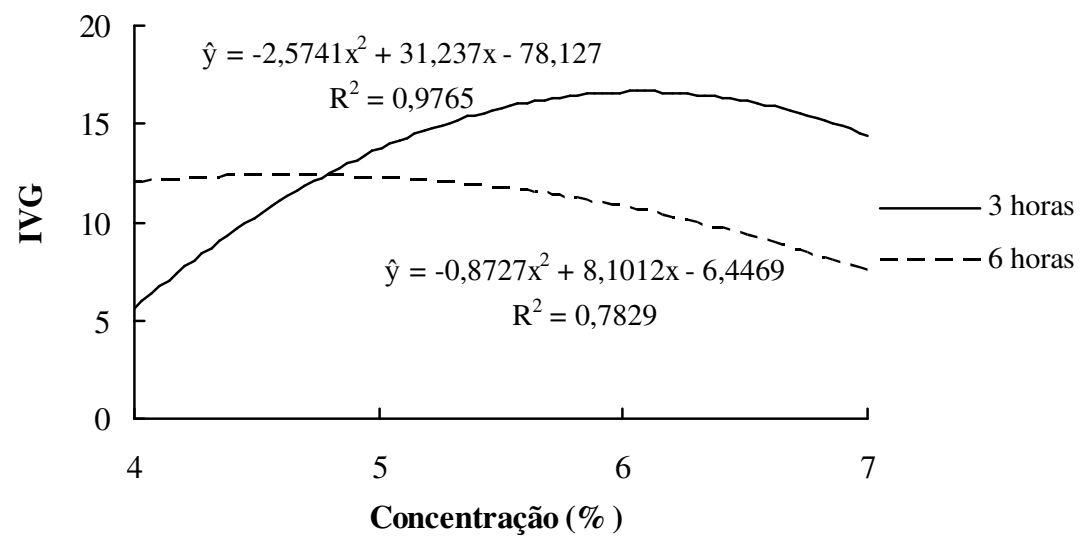

FIGURA 8. Índice de velocidade de germinação de sementes de café com umidade inicial de $30 \%$, após tratamento com hipoclorito de sódio nas concentrações de 4, 5, 6 e 7\% por períodos de 3 e 6 horas. 


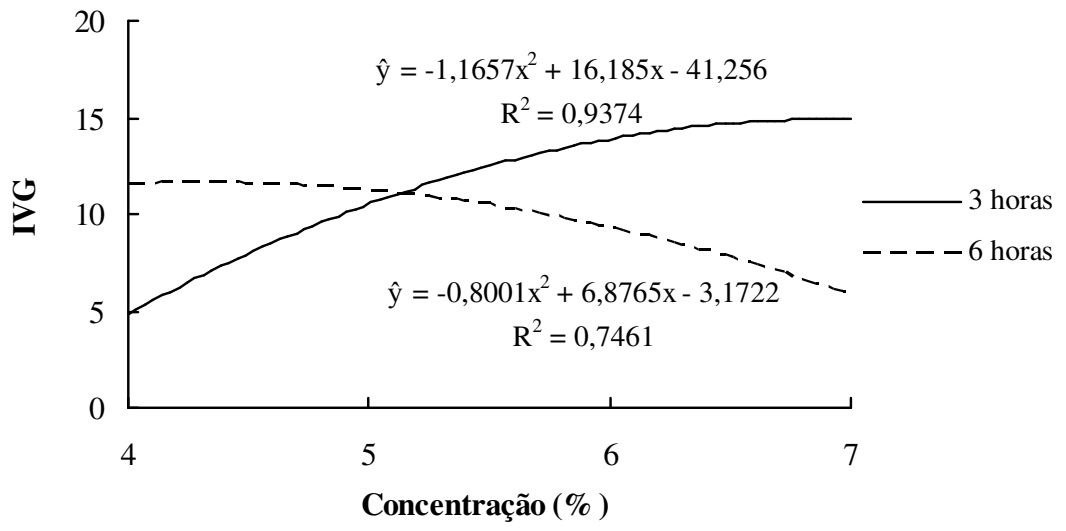

FIGURA 9. Índice de velocidade de germinação de sementes de café com umidade inicial de $25 \%$, após tratamento com hipoclorito de sódio nas concentrações de 4, 5, 6 e 7\% por períodos de 3 e 6 horas.

Na Tabela 4, observa-se que o tratamento prégerminativo em solução de hipoclorito de sódio na concentração de $6 \%$ durante 3 horas foi semelhante ao tratamento de remoção manual do pergaminho, para todas as umidades, demonstrando ser eficiente na aceleração da germinação das sementes. Para os graus de umidade de 25 e $30 \%$, a concentração de $7 \%$ por 3 horas também proporcionou velocidade de germinação similar às sementes que tiveram o pergaminho removido manualmente.

TABELA 4. Índice de velocidade de germinação, de sementes de café conilon com graus de umidade inicial de 35, 30 e $\mathbf{2 5 \%}$, após tratamento de remoção do pergaminho.

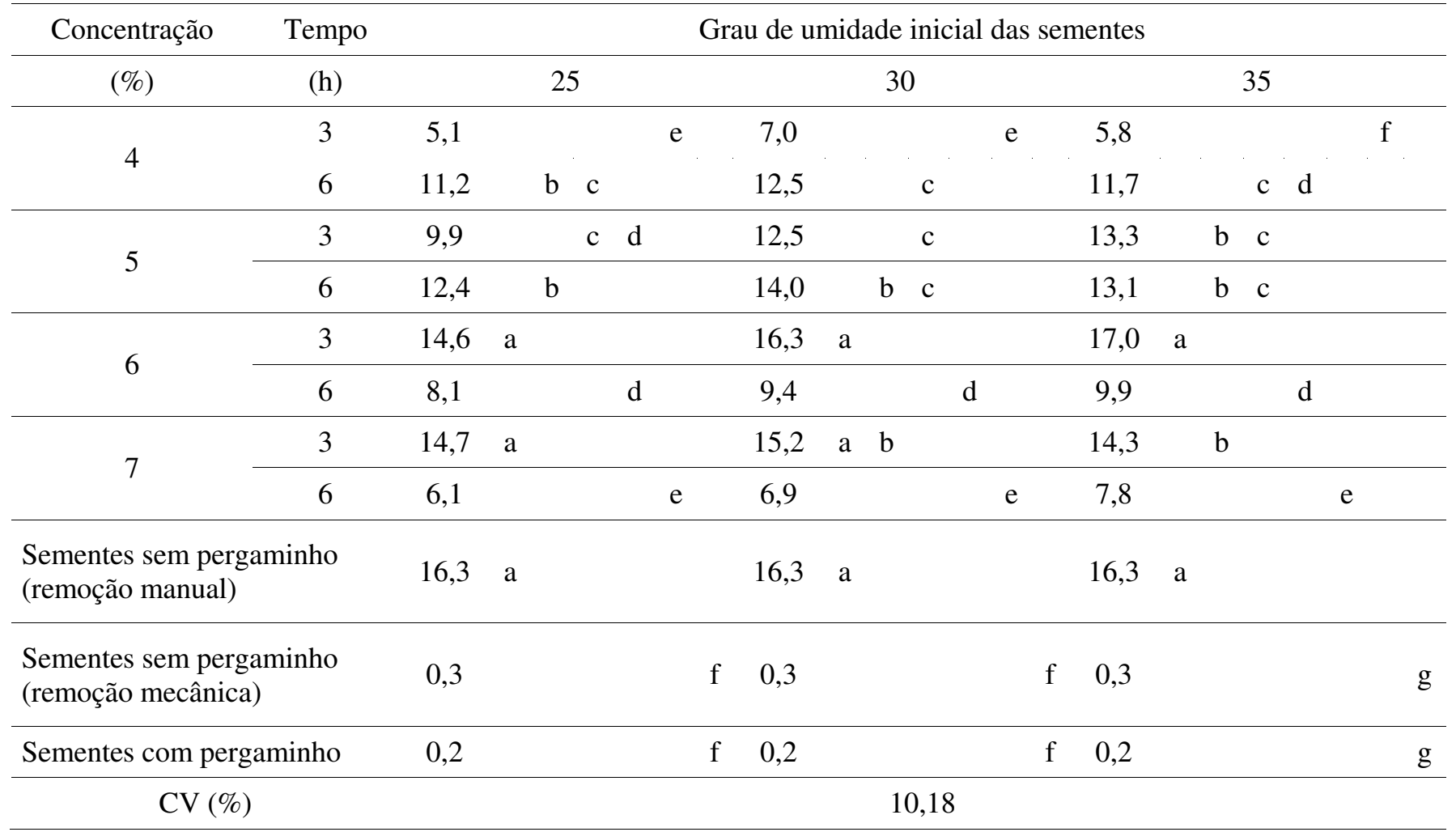

Médias seguidas pela mesma letra na coluna não diferem entre si ao nível de 5\% de probabilidade pelo teste de Tukey. 
Esses resultados corroboram com Sofiatti et al. (2008), os quais observaram que sementes de café arábica tratadas com hipoclorito de sódio na concentração de $6 \%$ por 3 horas tiveram IVG semelhante à testemunha (remoção manual do pergaminho), em sementes com 23, 28 e 33\% de umidade.

A velocidade de germinação das sementes com pergaminho e sementes cujo pergaminho foi removido mecanicamente foi extremamente prejudicada.

\section{CONCLUSÕES}

A germinação e vigor das sementes de café conilon com umidade de $25 \%, 30 \%$ ou $35 \%$ não são alterados quando o pergaminho é removido pela imersão em hipoclorito de sódio na concentração de $6 \%$ de cloro ativo, por um período de 3 horas.

A submersão de sementes de café conilon, com qualquer umidade, em soluções de hipoclorito de sódio na concentração de $7 \%$ de cloro ativo, reduz significativamente a germinação.

A remoção mecânica do pergaminho danifica as sementes de café Conilon.

\section{REFERÊNCIAS}

ANDRADE, E.T.; CORRÊA, P.C.; MARTINS, J.H., ALVARENGA, E.M. Avaliação de dano mecânico em sementes de feijão por meio de condutividade elétrica. Revista Brasileira de Engenharia Agrícola e Ambiental, v.3, n.1, p.54-60, 1999.

ARAÚJO, E.F.; REIS, L.S.; MEIRELES, R.C.; SERRANO, L.A.L. Efeito da danificação mecânica e da remoção manual do pergaminho sobre a emergência de plântulas de Coffea arabica L. Revista Brasileira de Armazenamento, v. Especial Café, n. 8, p.1-5, 2004.

BEWLEY, J.D.; BLACK, M. Physiology and biochemistry of seeds in relation to germination: viability, dormancy and environmental control. Berlin: Springer - Verlag, 1982. 375p.
BRASIL. Ministério da Agricultura e Reforma Agrária. Secretaria Nacional de Defesa Agropecuária. Departamento Nacional de Defesa Vegetal. Coordenação de Laboratório Vegetal. Regras para análise de sementes. Brasília, DF, 1992. 365p.

CARNELOSSI, M.A.G.; LAMOUNIER, L.; RANAL, M.A. Efeito da luz, hipoclorito de sódio, escarificação e estratificação na germinação de sementes de alface (Lactuca sativa L.) cv. Maioba e Moreninha-de-Uberlândia. Pesquisa Agropecuária Brasileira, v.30, n.6, p.779-787, 1995.

FRANCO, C.M. Apontamentos de fisiologia do cafeeiro. Instituto Agronômico de Campinas, 1970. 32p.

GUIMARÃES， R.J.; MENDES，A.N.G. Morfologia/ Fisiologia do cafeeiro. Lavras: UFLA/FAEPE, 1998. 28p.

MAGUIRE, J.D. Speed of germination-aid in selection and evaluation for seedling emergence and vigour. Crop Science, v.2, n.2, p.176-177, 1962.

MEIRELES, R.C. Efeito do hipoclorito de sódio e da embebição em água na germinação de sementes de café (Coffea arabica L.). 2004. 56f. Dissertação (Mestrado em Fitotecnia). Departamento de Fitotecnia, Universidade Federal de Viçosa, Viçosa.

MEIRELES, R.C.; ARAÚJO, E.F.; REIS, M.S.; SEDIYAMA, C.S.; SAKIYAMA, N.S.; REIS L.S. Secafé: Metodologia para acelerar a germinação das sementes de café. Revista Brasileira de Sementes, v.29, n.3, p.80-86, 2007.

SEAGRI. Secretaria de Agricultura, Irrigação e Reforma Agrária. Cultura Café Conilon. Disponível em:http:// www.bahia.ba.gov.br/seagri/caféconilon.htm. Acesso em: 22 dez. 2008.

SOFIATTI, V.; ARAÚJO, E.F.; ARAÚJO, R.F.; REIS, M.S.; SILVA, L.V.B.D.; CARGNIN, A. Uso do hipoclorito de sódio para degradação do endocarpo de sementes de cafeeiro com diferentes graus de umidade. Revista Brasileira de Sementes, v.30, n.1, p.150-160, 2008.

VALIO, I.F.M. Inhibition of germination of coffee seeds (Coffea arabica L. cv. Mundo Novo) by the endocarp. Journal of Seed Technology, v.5, n.1, p.32-39, 1980. 